\title{
Effects of Storage Conditions on the Total Content of Anthocyanins and Degradation of Phenolic Compounds During Long Storage of Pomegranate Fruit (Punica Granatum L.)
}

Elham Lashkari ( $\square$ lashkari3lham@gmail.com ) Johns Hopkins University

\section{Research Article}

Keywords: Pomegranate, Anthocyanins, degradation of phenolic compounds, Storage, Packaging, postharvest

Posted Date: December 10th, 2021

DOI: https://doi.org/10.21203/rs.3.rs-1149948/v1

License: (c) (1) This work is licensed under a Creative Commons Attribution 4.0 International License. Read Full License 


\section{Abstract}

Effects of storage temperature, elevated $\mathrm{CO} 2$ and reduced 02 in the package headspace, packaging material, and their interactions on the total content of anthocyanins and degradation of phenolic compounds in 'Malase Torsh Saveh' pomegranate were studied during long storage. The results showed that only storage temperature and its duration had significant effects on the degradation of phenolic compounds. The content of anthocyanins was affected by the single effect of storage time and its 3-way interaction effect with the storage temperature and the surrounding gas composition. Higher amounts of both total anthocyanins and browning pigments were recorded at $2{ }^{\circ} \mathrm{C}$. The Browning index (BI) of the pomegranate extracts changed quadratically with the variations in the total anthocyanins content and linearly with the variations in the content of browning compounds. Thermal dipping treatment and its interaction with the storage time significantly affected the BI values of modified atmosphere packaged pomegranates stored at $6{ }^{\circ} \mathrm{C}$.

\section{Highlights}

- Total content of anthocyanins in all treatments were reduced during cold storage.

- Development of browning pigments in the arils was induced by the elevated $\mathrm{CO} 2$ at $2{ }^{\circ} \mathrm{C}$.

- Browning index is more influenced by the variations in the content of anthocyanins.

- Thermal dipping treatment enhanced browning index of fruits with MAP during storage.

\section{Introduction}

The role of phenolic compounds in food quality, their health-promoting and therapeutic effects, along with their mechanism of actions on human health has been the topic of numerous researches in recent years. In addition to their health beneficial properties, phenolic compounds are connected with the quality of plant-derived foods such as appearance, color, taste and aroma. Pomegranate fruit (Punica granatum L.) is quite well-known for its nutritious nature and presenting an array of health beneficial activities, in particular antioxidative, anti-inflammatory, anti-carcinogenic, antimicrobial, neuro- and cardio-protective properties [1-6].

Most of these biological properties are attributed to the pomegranate's primary and secondary metabolites in specific phenolic compounds such as anthocyanins, flavanols, ellagi- and gallotannins, proanthocyanidins, and lignans [5, 7-10]. These phenolic compounds are found in all parts of the fruit, including fruits peel (ellagitannins, phenolic acids, flavonoids), arils (flavonoids, hydrolysable and condensed tannins, and phenolic acids), seeds (phenolic acids, flavonoids, hydrolysable tannins), and membrane walls (mostly ellagitannins) [11-15]. As illustrated in Figure 1, pomegranate phenolic compounds possess very diverse chemical structures and appear in different quantities depending on the plant cultivar, geographical, agronomic, and other environmental factors such as postharvest handling and storage conditions [16-19]. 
Scientific researches have provided evidence that the type of technologies and treatments being applied during postharvest handling and storage have significant impact on the total contents of phenolic compounds, their biosynthesis, metabolism, biological activities and the involved enzymatic reactions $[16,20-23]$. These effects could be either favorable or unfavorable towards preserving the desired quality of the pomegranate fruit [16]. Therefore, current studies are also focused on finding technologies or a combination of them that are able to maintain the original quality of this fresh produce-color, flavor, texture- and its nutritious compounds e.g., vitamins, sugars, amino acids, antioxidants, and other healthpromoting compounds, while avoiding weight loss, fungal decay, and common physiological disorders such as husk scald, pitting, and chilling injury during cold storage.

Various studies have shown that modified atmosphere packaging (MAP) technology by decreasing the oxygen content and/or increasing the carbon dioxide content of the atmosphere surrounding the fresh produce, can delay quality loss, tissue softening, enzymatic activities, and incidence of various physiological disorders and pathogenic developments during long storage of pomegranate fruit [20-21, 23-31]. MAP can also prevent the fruit weight loss and shriveling by creating a higher relative humidity in the surrounding environment of the fruit. Consequently, MAP may be applied or combined with other storage treatments to inhibit potential development of any decay or physiological disorders, for instance application of MAP with various thermal treatments, refrigeration, etc. [16, 32].

Nonetheless, identifying the applicable MAP that obtained the desired outcome in terms of maintaining the quality and nutritional aspects while avoiding decay and unwanted physiological disorders during long storage require extensive scientific studies. The optimum MAP can vary for one pomegranate to another depending on the cultivar, packaging material, and other storage conditions in particular temperature [27]. Within this context, the aims of this study were (1) to determine the effects of MAP technology on the total contents of anthocyanins and degradation of phenolic compounds during cold storage of pomegranate fruit cv. 'Malase Torsh Saveh', and (2) to investigate the effects of combination of dipping thermal treatment \& MAP technology on the total contents of anthocyanins and degradation of phenolic compounds of pomegranates during cold storage. This research is the first study that investigates the effects of MAP technology on the phenolic compounds of pomegranate fruit cv. 'Malase Torsh Saveh' during long storage.

\section{Materials And Methods}

\subsection{Materials}

2.1.1. Plant material: Pomegranate fruits (Punica granatum L.) cultivar 'Malase Torsh Saveh', which is a popular commercial cultivar in Iran were harvested on October $23^{\text {rd }}$ from Saveh Pomegranate Research Station. Harvested fruits were stored overnight in the research cold room at $4-5^{\circ} \mathrm{C}$, and pomegranates with uniform size, shape, appearance, and sound outer skin were sorted for the study the day after. 
2.1.2. Chemicals and other materials: The unperforated low-density polyethylene (LDPE) and polypropylene (PP) packaging bags were procured from a local provider. Citric acid, sodium citrate, and sodium hydroxide were purchased from Merck KGaA (Darmstadt, Germany).

\subsection{Methods}

2.2.1.1. Sample preparation: For the purpose of effect screening, selected pomegranates were divided into different groups with two storage temperatures of $2 \& 6^{\circ} \mathrm{C}$, two packaging materials of unperforated PP and LDPE, and two modified headspace gas compositions coded as GC1 and GC2 with elevated amounts of $\mathrm{CO} 2$ and reduced $\mathrm{O} 2$ compare to the ambient atmosphere. The two control groups consist of 60 coded pomegranates with no polymeric packaging that were evenly placed inside wooden trays and stored at the ambient atmosphere of $2 \& 6^{\circ} \mathrm{C}$ cold rooms with $85-90 \% \mathrm{RH}$ throughout the study.

The one-chamber table-top packaging machine (Henkelman 200A, Denmark) was used to flush and insert the programmed gas mixtures inside the unperforated LDPE and PP bags. The two gas mixture compositions that applied prior the storage phase coded as GC1 with 5\% CO2+5\% 02 and GC2 with 10\% $\mathrm{CO} 2+5 \% \mathrm{O} 2$ gas composition respectively. Nitrogen gas made the remaining component of both mixtures. All sealed packages that each contains a pair of pomegranates were checked and then transferred to the 2 and $6{ }^{\circ} \mathrm{C}$ cold rooms for the long storage.

2.2.1.2. Thermal dipping treatment: to investigate the potential effects of thermal dipping treatment on the total anthocyanins and phenolic compound contents of packaged fruits during long storage, 60 pomegranates were selected and divided into two groups. Half of these fruits were dipped in the $46{ }^{\circ} \mathrm{C}$ water bath (Tattnauer, NY, USA) for 2 minutes and left to completely air-dry prior to packaging. After they completely dried, they were coded and placed inside the unperforated LDPE bags in pairs (2 pomegranates in each package). The package headspace of both sampling groups was replaced with the gas composition of $5 \% \mathrm{CO} 2+5 \% \mathrm{O} 2(\mathrm{GC} 1)$ and got sealed immediately. Both groups were stored at the cold room of $6{ }^{\circ} \mathrm{C}$ for a duration of 12 weeks.

\subsubsection{Quantification of total anthocyanins and phenolic degradation compounds}

To measure the total anthocyanin contents and phenolic compound degradation products of the stored fruits, first three pomegranates were randomly selected from each sampling group. Then they were halfcut with a clean knife and the juice from the arils was extracted by using a manual stainless-steel juice squeezer. Next the extracted juices were centrifuged (Andreas Hettich centrifuge, Germany) for 20 min at $3000 \mathrm{rpm}$ and the supernatant of the samples were used for the spectrophotometry measurements. Juice absorbance values were obtained by diluting the juice supernatant with citric acid buffer $(\mathrm{pH}=3.4)$ for maximum stability of anthocyanins at 1:3 (v/v) ratio. Later, the total anthocyanin contents of the extracts were recorded by measuring the absorbance at $510 \mathrm{~nm}$ with the UV/Vis spectrophotometer instrument (Perkin Elmer Lambda EZ 201, MA, USA) and obtained values were reported as the Absorbance Unit (AU), which is also expressed as the optical density (OD) per unit length (the cuvette thickness used in this study was $1 \mathrm{~cm}$ ): 
$O D_{\lambda}=\frac{A_{\lambda}}{l}$

Where:

I = the distance that light travels through the sample (the sample thickness) measured in $\mathrm{cm}$

$A_{\lambda}=$ absorbance at wavelength $\lambda$

Absorbance at wavelength of $446 \mathrm{~nm}$ were recorded by the same spectrophotometer as an indication of polymerization and degradation of phenolic compounds or production of browning compound. Citric acid buffer ( $\mathrm{pH}=3.4)$ was used as the reference solution for the absorbance measurements at both 510 and $446 \mathrm{~nm}$ wavelengths [20-21, 25-26]. All measurements were performed in triplicate.

\subsubsection{Browning Index (BI) calculation}

Browning index of the extracted juice which reflects the ratio of the total anthocyanin to the development of browning compound or phenolic degradation products was calculated for all sampling groups from equation 2 [33].

$$
B I=\frac{\text { Absorbance at } 446 \mathrm{~nm}}{\text { Absorbance at } 510 \mathrm{~nm}}
$$

\subsubsection{Determination of $\mathrm{pH}$, titratable acidity (TA), \& total soluble solids (TSS)}

4 grams of the extracted juice was diluted with $20 \mathrm{~mL}$ of HPLC grade distilled water, and values of $\mathrm{pH}$ were measured by the $\mathrm{pH}$ meter (744 HannaTM porable $\mathrm{pH}$ meter, Portugal) according to Hess-Pierce \& Kader, 2003 [26]. Titratable acidity was determined by titrating the diluted juice with $0.1 \mathrm{~N} \mathrm{NaOH}$ to $\mathrm{pH}=8.1-8.3$ and results were reported as (\%) or gr Citric acid per $100 \mathrm{gr}$ of juice. The TSS of the extracted juice was measured by using a refractometer (Bellingham + Stanley, U.K.) at $20^{\circ} \mathrm{C}$.

\subsubsection{Statistical analysis}

Storage temperature with 2 levels $\left(2\right.$ and $\left.6{ }^{\circ} \mathrm{C}\right)$, Packaging type with 3 levels (LDPE, PP, and no packaging or None), head space gas composition with 3 levels (air or ambient atmosphere, GC1, \& GC2), and storage time with 4 levels (3 weeks intervals) were applied as the experimental design factors. The effect of hotwater pretreatment on the LDPE packaged pomegranate fruits stored at $6{ }^{\circ} \mathrm{C}$ was studied on 2 groups for 12 weeks and analyzed separately. All measurements were conducted in 3 replicates and the mean value was reported. JMP Pro software was used to perform the statistical analysis and for data visualization. Analysis of variance (ANOVA) at $\mathrm{P}<0.05$ and Student's t Test (for mean comparison) were applied when appropriate.

\section{Results}




\section{1. Changes in the total content of anthocyanins}

Among the multiple factors being studied, only the single effect of storage time was found to have significant effect on the total content of anthocyanins at $p<0.01$ during this study. The results showed a decline from the average absorbance value of $0.917 \pm 0.054$ (Mean \pm SE) at the beginning of the study through the 7th week of the storage which followed by a slight increase towards the end of the study $(0.49 \pm 0.054)$. The total content of anthocyanins was also affected by the 3-way interaction effects of the storage duration, storage temperature, and the surrounding gas composition. Overall, samples with MA packaging displayed lower values of total anthocyanins around the seventh week of storage compared to the control samples with no packaging (Figure 2). Among the MA packaged treatments, storage temperature of $2{ }^{\circ} \mathrm{C}$, LDPE packaging, and initial gas mixture of $5 \% \mathrm{CO} 2+5 \%$ O2(GC1) were associated with higher amounts of total anthocyanin contents by the end of study. The interaction profile (Figure 3 ) also indicates an interaction between the storage temperature and the packaging type although it was not found to be statistically significant. Besides, higher amounts of anthocyanins were observed on average in the extracts of samples that were stored at $2{ }^{\circ} \mathrm{C}$ storage temperature compared to samples that were stored at $6^{\circ} \mathrm{C}$ during long storage regardless of their packaging type and the surrounded atmospheric composition.

\section{2. Changes in the degradation of phenolic compounds}

The results of this study showed that the single effects of storage time and temperature have had significant effects on the degradation of phenolic compounds and formation of browning pigments at $p<0.05$. On average higher amount of phenolic compounds degradation products was observed by the end of study $(0.332 \pm 0.024)$ compared to the beginning of the study $(0.278 \pm 0.024)$ in spite of fluctuations over 10-weeks of storage. Likewise, degradation of phenolic compounds was enhanced at $2{ }^{\circ} \mathrm{C}$ storage temperature with the average absorbance value of $0.323 \pm 0.017$ at $446 \mathrm{~nm}$ compared to $0.264 \pm 0.017$ when samples were stored at $6{ }^{\circ} \mathrm{C}$ temperature (Figure 4). None of the $2 \& 3$-way interaction effects were found to be significant. Yet, the interaction profile (Figure 5) displayed an interaction between the storage temperature and the type of packaging that may not be statistically significant. As shown in Figure 5 storage temperature of $2{ }^{\circ} \mathrm{C}$, PP packaging, and initial gas mixture of $5 \% \mathrm{CO} 2+5 \%$ O2(GC1) induced higher amounts of degradation in phenolic compounds and subsequent formation of browning pigments among MA packaged pomegranate fruits. Extracts of pomegranates that were stored with no packaging and surrounded by the ambient atmosphere of the cold room showed the least amounts of browning pigments on average at the end of study (Figure 4, bottom).

\section{3. Changes in the Browning Index (BI)}

The results of the data analysis indicates that the Browning Index was affected by the single effect of the storage time, its 2-way interaction effects with the packaging type, and its 3-way interaction effects with storage temperature and the surrounding atmospheric composition at $p<0.01$. The average $B I$ value was increased from $0.31 \pm 0.02$ at the beginning of the study to $0.69 \pm 0.04$ by the end of study. The increase occurred during the first 4 weeks of the storage and remained around the same value during the rest of 
the 10-week study. Extracts of pomegranates that were stored without packaging and surrounded by the ambient atmosphere displayed the lowest values of $\mathrm{BI}(0.53 \pm 0.06)$ at the end of the storage time compared to the MA packaged treatments. Whereas, extracts of pomegranates with PP packaging showed the highest BI value $(0.63 \pm 0.06)$ at the end of study (Figure 6, top). Also, the lowest BI values obtained from treatments that were stored in the ambient atmosphere compared to the values recorded for the other two MA gas compositions. Overall higher BI values were associated with storage temperature of $2^{\circ} \mathrm{C}$. Control samples with no packaging and surrounded by the ambient atmosphere showed higher $\mathrm{BI}$ values when stored at $6^{\circ} \mathrm{C}$. In contrast to air-stored samples, the extracts of MA packaged pomegranates displayed higher $\mathrm{BI}$ values when stored at $2{ }^{\circ} \mathrm{C}$ cold room (Figure 6 , bottom).

\section{4. Changes in $\mathrm{pH}, \mathrm{TA}$, \& total soluble solids (TSS)}

Storage time showed significant effect at $\mathrm{p}<0.01$ on the $\mathrm{pH}$ values of the treatments over the course of study. The pH values displayed an increase from $3.45 \pm 0.05$ at the harvest to $3.67 \pm 0.17$ during the first month of storage which remained around the value of $3.64 \pm 0.19$ till the end of 10 weeks of storage. $\mathrm{pH}$ was not influenced significantly by the storage temperature; however, it was affected by the 2- \& 3-way interaction effects of storage time with packaging type \& gas composition $(p<0.01)$. Overall, the control samples that were surrounded by the ambient atmosphere and had no packaging showed $\mathrm{pH}$ values closer to the $\mathrm{pH}$ at the harvest $(\mathrm{pH}=3.53 \pm 0.03)$. Whereas extracts from pomegranates that had PP packaging and packaged with initial gas mixture of $5 \% \mathrm{CO} 2+5 \%$ O2(GC1) were associated with higher values of $\mathrm{pH}$ at the end of 10 weeks of storage with the average $\mathrm{pH}$ values of $3.66 \pm 0.03$ and $3.63 \pm 0.02$ respectively (Figure 7, top).

TA values were significantly affected by the single effect of gas composition and its interaction with the storage duration $(p<0.01)$. The average TA values displayed slight decrease from the TA at the harvest $(1.02 \pm 0.032 \%)$ until the 7 th week of storage $(0.918 \pm 0.032 \%)$ and then started to slowly increase toward the end of the study $(0.974 \pm 0.032 \%)$. As shown in Figure 7 (bottom), the control samples that were surrounded by the ambient atmosphere and had no packaging showed higher amounts of TA, while the samples with PP packaging and the initial gas mixture of 5\% $\mathrm{CO} 2+5 \% \mathrm{O} 2(\mathrm{GC} 1)$ showed the lowest values for TA by the end of study. These results are in agreement with the study findings on $\mathrm{pH}$ changes throughout the storage. Also, pomegranates that were packaged with the initial gas mixture of $10 \% \mathrm{CO}+$ $5 \%$ O2(GC2) exhibited lowest $\mathrm{pH}$ values $(\mathrm{pH}=3.5)$ and highest TA $(\mathrm{TA}=1.19 \%)$ values by the end of study which suggests the potential slow penetration of $\mathrm{CO} 2$ gas within the pomegranate fruit tissues including arils which has led to the formation of carbonic acid and subsequently reduction in $\mathrm{pH}$ and increase of the titratable acidity (TA). These changes are particularity observable from the seventh week of storage.

The values of total soluble solids (TSS) were affected only by the storage duration at $p<0.05$ and none of the other factors-storage temperature, gas composition, and type of packaging- and their 2- and 3-way interactions was found to be significant. The average TSS values showed slight decrease from $18.17 \pm 0.13$ at the harvest to $17.57 \pm 0.13$ by the end of storage which indicates minor loss of saugers due to the low respiratory activities of pomegranate fruit during the long storage. 


\section{5. Effects of Thermal Dipping (TD) treatment}

The results show that the single effect of thermal dipping (TD) treatment was not significant on the total content of anthocyanins, degradation of phenolic compounds, and Browning Index during the long storage. However, as shown in Table 1. the 2-way interaction effect of thermal dipping treatment with the storage time had significant effect (at $p<0.01$ ) on the values of the Browning Index. The extracted juice obtained from pomegranates that received TD treatment prior to the storage had higher BI value (mean $\mathrm{BI}=0.95$ ) compared to the control group (mean $\mathrm{BI}=0.66$ ) after 12 weeks of study (Figure 8).

The values of $\mathrm{pH}, \mathrm{TSS}$, and TA were not affected by the single effect of TD treatment. Still, the 2-way interaction effect of thermal dipping treatment with storage time was found to have significant effects on the values of $\mathrm{pH}($ at $p<0.01)$, TSS (at $p<0.05)$, and TA (at $p<0.05)$. By the end of 12 weeks of storage, the extracted juice of samples that had received TD treatment showed higher $\mathrm{pH}$ \& lower TA and TSS values compared to the control samples that have not received thermal dipping treatment.

\section{Discussion}

The findings of this study showed an overall decrease in the total contents of anthocyanins during 10 weeks of storage, in which multiple factors might have been involved. Some of the factors that affect anthocyanins stability or their susceptibility to degradation are temperature, increased sugar, $\mathrm{pH}$, and acidity level, metal chelation, and copigmentation with other flavonols and tannins [19, 34]. Likewise, regulation and activity of phenylalanine ammonia-lyase (PAL), which is the key enzyme in biosynthesis of flavonoids can be another influential factor [16]. Therefore, the overall decline in the contents of anthocyanins during the storage could be to some extent as the result of effects of cold storage temperature on the enzymatic activities of PAL that has inversely affected the biosynthesis of anthocyanins. Similarly, the pomegranate extracts that obtained from MA packaged samples showed less absorbance at $510 \mathrm{~nm}$ compared to those obtained from air-stored pomegranates, which is even more evident by the seventh week of storage. These findings are consistent with the findings of previous studies on MAP of 'Mollar de Elche' and 'Wonderful' pomegranate cultivars, suggesting elevated amounts of $\mathrm{CO} 2$ in the surrounding atmosphere of stored pomegranates might have a role in disrupting the PAL activity that subsequently led to the suppression of anthocyanins biosynthesis and pigmentation [25-26, 34]. Additionally, $\mathrm{pH}$ reduction and TA increase as the result of gradual penetration of $\mathrm{CO} 2$ in tissues and arils of MA packaged pomegranates and potential formation of carbonic acid could be another contributing factor to the anthocyanins' stability and their noticeable increase from week 7 th of storage towards the end of the 10-week study. So, despite the lack of significant difference among the anthocyanin contents of control and MA packaged pomegranates by the end of study, yet different underlying factors might have been participated throughout the storage.

Nonetheless, a different pattern in the contents of anthocyanins was reported during the cold storage of MA packaged 'Hicaznar' and 'Hicrannar' cultivars. Selcuk \& Erkan (2014) reported an increase in the total anthocyanin contents of 'Hicrannar' pomegranates during the first 100 days of storage at $6^{\circ} \mathrm{C}$ that 
followed by a decrease over the last 20 days of study in both MAP and control treatments through 120 days of storage [28]. Total anthocyanin contents in 'Assaria' pomegranates that were subjected to several storage treatments also showed an increase during the first month of storage with continued decrease towards the end of 4 months of cold storage at $5{ }^{\circ} \mathrm{C}$ [22]. 'Ruby' pomegranates when air-stored at 5 and 7 ${ }^{\circ} \mathrm{C}$ for 16 weeks displayed an increase in their anthocyanin concentration through 8 and 12 weeks of storage that followed by a slight decrease and no change in their content correspondingly till the end of cold storage [35]. Selcuk \& Erkan (2015) and Çandir et al. (2018 \& 2019) also reported an overall increase in the anthocyanin content of 'Hicaznar' pomegranates during the first 4 months of cold storage and a gradual decrease in the anthocyanin content toward the end of storage in both air-stored \& MA packaged pomegranates when stored at $6^{\circ} \mathrm{C}$ for 6 months [23, 30-31]. Yet, Çandir et al. (2018) observed delayed anthocyanins synthesis and lower anthocyanin concentrations in MA packaged 'Hicaznar' pomegranates [30]. The difference in the anthocyanins pattern of changes during long storage can be attributed to the inherent differences among various cultivars considering the same trend that have been recorded for both control and MA packaged pomegranates during long storage that indicates the potential continued postharvest metabolic activities including biosynthesis of anthocyanins in the fruit despite of being refrigerated and/or subjected to the MA packaging.

The study results also showed higher contents of browning pigments due to the degradation of phenolic compounds when pomegranates stored at $2{ }^{\circ} \mathrm{C}$ compared to $6{ }^{\circ} \mathrm{C}$ storage temperature. These findings can be attributed to the enzymatic activities of polyphenol oxidases (PPO) and peroxidases (POD) that catalyzed enzymatic browning in fruit tissues as the results of environmental stresses such as low storage temperatures and mechanical injuries [16]. Likewise, elevated $\mathrm{CO} 2$ contents in the surrounding atmosphere of MA packaged pomegranates can be another contributing factor that enhanced polymerization of phenolic compounds in the tissues and arils of MA packages pomegranates compared to the control samples. These observations are consistent with the findings reported for 'Mollar de Elche' pomegranates when packaged with CO2-enriched MA and stored at $5{ }^{\circ} \mathrm{C}$ for 12 weeks [25]. The results of this study also recorded higher amounts of browning pigments over the storage time that can be an indication of PPO and POD enzymatic activities as the results of minor incident of chilling injury in the tissues that often led to development of browning pigments in pomegranates when stored at low temperatures for a long time.

As shown in Figure 9, the variations in the browning index $(\mathrm{BI})$ values during long storage is more influenced by the variation in the total contents of anthocyanins rather than degradation of other phenolic compounds, which is an interesting finding and implies that anthocyanins are the main phenolic compounds in the arils. Likewise, these results indicate minor development of browning pigments as the result of degradation of phenolic compounds other than anthocyanins during 10 weeks of storage. These observations are even more noticeable at $2{ }^{\circ} \mathrm{C}$ storage temperature given that $2{ }^{\circ} \mathrm{C}$ is also associated with higher contents of both total anthocyanins and development of browning pigments. These results show the effects of low temperatures on the regulations and activities of the enzymes that are involved in the biosynthesis of phenolic compound such as anthocyanins and those that are participating in the enzymatic browning as the results of the incidence physiological disorders due to the environmental 
stresses such as long storage at low temperatures or elevated CO2 contents in the surrounding atmosphere of the fruit. As presented in Figure 10, the values of the BI of the extracts change quadratically with the variations in the contents of total anthocyanins but linearly with the variations in the contents of the browning compounds. Consequently, the prediction profiles can be used to determine the optimum anthocyanin contents and storage conditions based on the desired BI value for the anticipated applications such as fresh consumption, processed food products for instance juices, jams, jellies, or as a value-added ingredient e.g., natural colorant, bioactives, etc.

The study results also revealed that thermal dipping (TD) treatment can affect the BI value of the pomegranate extracts by enhancing degradation of anthocyanins, their polymerization, and subsequent formation of browning compounds throughout the storage. The increase in the BI value of the samples that received TD treatment is more visible from the nineth week of the study. Similarly, the significant 2way interaction effect of TD with the storage duration on $\mathrm{pH}, \mathrm{TA}$, and TSS variations during long storage of MA packaged pomegranates indicates the potential impact of TD on higher metabolisms of soluble solids-mainly sugars such as glucose, fructose, and arabinose-and organic acids (e.g., citric acid) in the pomegranates that have been subjected to the thermal treatment compared to the control group. Nonetheless, the TSS/TA ratio of pomegranates was not significantly affected (data not shown here) by TD treatment after 12 -weeks of storage at $6^{\circ} \mathrm{C}$.

\section{Conclusion}

In summary, the total contents of anthocyanins in 'Malase Torsh Saveh' pomegranates declined through 10 weeks of storage in all treatments. Among samples with MA packaging, pomegranates with LDPE packaging and the initial gas composition of $5 \% \mathrm{CO} 2+5 \% 02$ in their package headspace maintained higher amounts of total anthocyanins when stored at $2{ }^{\circ} \mathrm{C}$. Nonetheless, higher incidence of browning pigments was also recorded at $2{ }^{\circ} \mathrm{C}$ possibly as the results of occurrence of minor chilling injury throughout the cold storage. Lesser browning pigments was developed among samples with MA packaging through the first seven weeks of storage, however their contents started to increase towards the end of study. The browning index $(\mathrm{BI})$ values of the extracts showed an overall increase throughout the storage and they were more influenced by the variations in content of total anthocyanins in the extracts rather than the content of browning pigments, which indicates minor development of browning pigments during the long storage. Pre-storage thermal dipping as a complementary treatment along with MAP showed no significant effects on the total content of anthocyanins, degradation of phenolic compounds, or development of browning compounds during the long storage. However, BI values of MA packaged pomegranates that had received TD prior to the storage started to significantly increase after 2 months of storage at $6{ }^{\circ} \mathrm{C}$.

\section{Declarations}

\section{Acknowledgments}


This research work was conducted at the Department of Food Science \& Technology, University of Tehran, College of Agriculture and Natural Resources, Karaj, Tehran. The author thanks Dr. Banafshe Lashkari, PhD, from University of Waterloo for her assistance in article retrieval.

\section{Declaration of competing Interest}

None

\section{Funding}

This research did not receive any specific grant from funding agencies in the public, commercial, or notfor-profit sectors.

\section{Ethics statement}

The author declares that this research work (a) is the author's own original work, (b) has not been published previously, and (c) is not under consideration for publication elsewhere.

\section{Data availability statement}

The datasets generated during and/or analyzed during the current study are available from the corresponding author on reasonable request.

\section{References}

1-Afaq F, Saleem M, Krueger CG, Reed JD, Mukhtar H. Anthocyanin- and hydrolysable tannin-rich pomegranate fruit extract modulates MAPK and NF-KB pathways and inhibits skin tumorigenesis in CD-1 mice. International Journal of Cancer. 2005; 113: 423-433. https://doi.org/10.1002/ijc.20587.

2-Reddy MK, Gupta SK, Jacob MR, Khan SI, Ferreira D. Antioxidant, antimalarial and antioxidant activities of tannin-rich fractions, ellagitannins and phenolic acids from Punica granatum L. Planta medica. 2007; 73(5): 461-467. https://doi.org/10.1055/s-2007-967167.

3-Haghayeghi K, Shetty K, Labbé R. Inhibition of foodborne pathogens by pomegranate juice. Journal of medicinal food. 2013; 16(5): 467-470. https://doi.org/10.1089/jmf.2012.0233.

4-Howell $A B$, D'Souza DH. The pomegranate: effects on bacteria and viruses that influence human health. Evidence-Based Complementary and Alternative Medicine. 2013; http://doi.org/10.1155/2013/606212.

5-Pepe G, Rapa SF, Salviati E, Bertamino A, Auriemma G, Cascioferro S, Autore G, Quaroni A, Campiglia P, Marzocco S. Bioactive polyphenols from pomegranate juice reduce 5 -fluorouracil-induced intestinal mucositis in intestinal epithelial cells. Antioxidants. 2020. https://doi.org/10.3390/antiox9080699.

6-Mukherjee S, Ghosh S, Choudhury S, Gupta P, Adhikary A, Chattopadhyay S. Pomegranate polyphenols attenuate inflammation and hepatic damage in tumor-bearing mice: crucial role of $\mathrm{nf}-\mathrm{kb}$ and the 
Nrf2/GSH Axis. Journal of Nutritional Biochemistry, 2021;

https://doi.org/10.1016/j.jnutbio.2021.108812.

7-Viuda-Martos M, Fernández-López J, Pérez-Álvarez J. Pomegranate and its many functional components as related to human health: A Review. Comprehensive Reviews in Food Science and Food Safety. 2010; 9: 635-654. https://doi.org/10.1111/j.1541-4337.2010.00131.x.

8-Gómez-Caravaca AM, Verardo V, Toselli M, Segura-Carretero A, Fernández-Gutiérrez A, Caboni MF. Determination of the major phenolic compounds in pomegranate juices by HPLC-DAD-ESI-MS. Journal of Agricultural and Food Chemistry. 2013; 61 (22): 5328-

5337. https://doi.org/10.1021/jf400684n.

9-Ambigaipalan P, de Camargo A, Shahidi F. Phenolic compounds of pomegranate byproducts (outer skin, mesocarp, divider membrane) and their antioxidant activities. Journal of Agricultural and Food Chemistry. 2016; 64 (34): 6584-6604. https://doi.org/10.1021/acs.jafc.6b02950.

10-Fahmy H, Hegazi N, El-Shamy S, Farag MA. Pomegranate juice as a functional food; A comprehensive review of its polyphenols, therapeutic merits, and recent patents. Food \& Function. 2020; 11: 5768-5781. https://doi.org/10.1039/d0fo01251c.

11-Ambigaipalan P, de Camargo A, Shahidi F. Identification of phenolic antioxidants and bioactives of pomegranate seeds following juice extraction using HPLC-DAD-ESI-MS. Food Chemistry. 2017; 221: 18831894. https://doi.org/10.1016/j.foodchem.2016.10.058.

12-Bar-Ya'akov I, Tian L, Amir R, Holland D. Primary metabolites, anthocyanins, and hydrolyzable tannins in the pomegranate fruit. Frontiers in Plant Science. 2019;

https://www.frontiersin.org/article/10.3389/fpls.2019.00620.

13-Díaz-Mula HM, Tomás-Barberán FA, García-Villalba R. Pomegranate fruit and juice (cv. Mollar), rich in ellagitannins and anthocyanins, also provide a significant content of a wide range of proanthocyanidins. Journal of Agricultural and Food Chemistry. 2019; 67(33): 9160-9167. https://doi.org/10.1021/acs.jafc.8b07155.

14-Fourati M, Smaoui S, Hlima HB, Elhadef K, Ben Braïek O, Ennouri K, Mtibaa AC, Mellouli L. Bioactive compounds and pharmacological potential of pomegranate (Punica granatum) seeds - A Review. Plant Foods for Human Nutrition. 2020; 75: 477-486. https://doi.org/10.1007/s11130-020-00863-7.

15-Hegazi MN, El-Shamy S, Fahmy H, Farag AM. Pomegranate juice as a super-food: A comprehensive review of its extraction, analysis, and quality assessment approaches.

Journal of Food Composition and Analysis. 2021; https://doi.org/10.1016/j.jfca.2020.103773.

16-Tomás-barberán FA, Espín JC. Phenolic compounds and related enzymes as determinants of quality in fruits and vegetables. Journal of Science of Food and Agriculture. 2001; 81: 853-876. 
https://doi.org/10.1002/jsfa.885.

17-Gözlekçi S, Saraçoğlu O, Onursal E, Ozgen M. Total phenolic distribution of juice, peel, and seed extracts of four pomegranate cultivars. Pharmacognosy magazine. 2011; 7(26): 161-164. https://doi.org/10.4103/0973-1296.80681.

18-Li X, Wasila H, Liu L, Yuan T, Gao Z, Zhao B, Ahmad I. Physicochemical characteristics, polyphenol compositions and antioxidant potential of pomegranate juices from 10 Chinese cultivars and the environmental factors analysis. Food Chemistry. 2015; 175: 575-584.

https://doi.org/10.1016/j.foodchem.2014.12.003.

19- Lee CY. Fruits and vegetables. In: DeMan JM, Finley JW, Hurst WJ, Lee CY. Principles of Food Chemistry. 4th edition. Switzerland. Springer; 2018. pp 435-455.

20-Gill MI, Sánchez R, Ginés Marín J, Artés F. Quality changes in pomegranates during ripening and cold storage. Z Lebensm Unters Forsch. 1996; 202: 481-485.

https://doi.org/10.1007/BF01197269.

21-Holcroft DM, Gil MI, Kader AA. Effect of carbon dioxide on anthocyanins, phenylalanine ammonia lyase and glucosyltransferase in the arils of stored pomegranates. Journal of American Society of Horticultural Science. 1998; 123(1): 136-140. https://doi.org/10.21273/JASHS.123.1.136.

22-Miguel G, Fontes C, Antunes D, Neves A, Martins D. Anthocyanin concentration of "Assaria" pomegranate fruits during different cold storage conditions. Journal of biomedicine \& biotechnology. 2004; 5: 338-342. https://doi.org/10.1155/S1110724304403076.

23-Selcuk N, Erkan M. Changes in phenolic compounds and antioxidant activity of sour-sweet pomegranates cv. 'Hicaznar' during long-term storage under modified atmosphere packaging. Postharvest Biology and Technology. 2015; 109: 30-39.

https://doi.org/10.1016/j.postharvbio.2015.05.018.

24-Beaudry R. Effect of $\mathrm{O} 2$ and $\mathrm{CO} 2$ partial pressure on selected phenomena affecting fruit and vegetable quality. Postharvest Biology and Technology. 1999; 16: 293-303. https://doi.org/10.1016/S09255214(98)00092-1.

25-Artés F, Villaescusa R, Tudela JA. Modified atmosphere packaging of pomegranate. Journal of Food Science. 2000; 65(7): 1112-1116. https://doi.org/10.1111/j.1365-2621. 2000.tb10248. x.

26-Hess-Pierce B, Kader AA. Responses of 'Wonderful' pomegranate to controlled atmospheres. Acta Horticulturae. 2003; 600: 751-757. https://doi.org/10.17660/ActaHortic.2003. 600.115.

27-Caleb OJ, Opara UL, Witthuhn CR. Modified atmosphere packaging of pomegranate fruit and arils: a review. Food and Bioprocess Technology. 2012; 5: 15-30. https://doi.org/10.1007/s11947-011-0525-7. 
28-Selcuk N, Erkan M. Changes in antioxidant activity and postharvest quality of sweet pomegranates cv. Hicrannar under modified atmosphere packaging. Postharvest Biology and Technology. 2014; 92: 29-36. https://doi.org/10.1016/j.postharvbio.2014.01.007.

29-Rao DV, Shivashankara KS. Effect of modified atmosphere packaging on the extension of storage life and quality maintenance of pomegranate (cv. 'Bhagwa') at ambient and low temperatures. Journal of food science and technology. 2018; 55(6): 2103-2113. https://doi.org/10.1007/s13197-018-3125-y.

\section{Bottom of Form}

30-Çandır E, Özdemir A, Aksoy M. Effects of chitosan and modified atmosphere packaging on postharvest quality and bioactive compounds of pomegranate fruit cv. 'Hicaznar'. Scientia Horticulturae. 2018; 235: 235-243. https://doi.org/10.1016/j.scientia.2018.03.017.

31-Çandır E, Özdemir A, Aksoy M. Effects of modified atmosphere packaging on the storage and shelf life of Hicaznar pomegranate fruits. Turkish Journal of Agriculture and Forestry. 2019; 43: 241253. https://doi.org/10.3906/tar-1801-119.

32-Artés F, Tomás-Barberán FA. Post-harvest technological treatments of pomegranate and preparation of derived products. In: Melgarejo P, Martínez-Nicolás JJ, Martínez-Tomé J. (Eds.), Production, processing and marketing of pomegranate in the Mediterranean region: Advances in research and technology. 2000: 199-204. Zaragoza: CIHEAM.

33-Muche BM, Speers RA, Rupasinghe H. Storage temperature impacts on anthocyanins degradation, color changes and haze development in juice of "Merlot" and "Ruby" grapes (Vitis vinifera). Frontiers in nutrition. 2005; https://doi.org/10.3389/fnut.2018.00100.

34-Gill MI, Holcroft DM, Kader AA. Changes in Strawberry anthocyanins and other polyphenols in response to carbon dioxide treatment. Journal of Agricultural and Food Chemistry.1997; 45: 16621667. https://doi.org/10.1021/jf960675e.

35-Fawole OA, Opara UL. Effects of storage temperature and duration on physiological response of pomegranate fruit. Industrial Crops and Products. 2013; 47: 300-309.

https://doi.org/10.1016/j.indcrop.2013.03.028.

\section{Tables}

\section{Table 1}

Analysis of thermal dipping treatment effect on the total anthocyanins, phenolic compounds degradation products, and browning index (BI) of the extracted juice of MA packaged pomegranates during long storage. 


\begin{tabular}{|c|c|c|c|c|c|c|c|c|}
\hline & Thermal & Treatment & & & & Thermal dippi & reatment & *Time \\
\hline & With & Without & & Time & & With & & Without \\
\hline & & & Wk. 1 & $0.917 \pm 0.052 a$ & Wk. 1 & $0.917 \pm 0.083 a$ & Wk. 1 & $0.917 \pm 0.083 a$ \\
\hline Absorption at $510 \mathrm{~nm}$ & & & Wk. 3 & $0.331 \pm 0.078 b$ & Wk. 3 & $0.464 \pm 0.11 b c$ & Wk. 3 & $0.197 \pm 0.017 \mathrm{~d}$ \\
\hline (Indicator of the extracted & $0.487 \pm 0.067 a$ & $0.480 \pm 0.073 a$ & Wk. 6 & $0.367 \pm 0.046 \mathrm{~b}$ & Wk. 6 & $0.394 \pm 0.084 \mathrm{bcd}$ & Wk. 6 & $0.340 \pm 0.053 \mathrm{bcd}$ \\
\hline juice total anthocyanins ) & & & Wk. 9 & $0.395 \pm 0.098 b$ & Wk. 9 & $0.263 \pm 0.045 \mathrm{~cd}$ & Wk. 9 & $0.528 \pm 0.1681 b$ \\
\hline & & & Wk. 12 & $0.409 \pm 0.022 b$ & Wk. 12 & $0.399 \pm 0.041 \mathrm{bcd}$ & Wk. 12 & $0.420 \pm 0.026 \mathrm{bcd}$ \\
\hline Absorption at $446 \mathrm{~nm}$ & & & Wk. 1 & $0.287 \pm 0.038 a$ & Wk. 1 & $0.287 \pm 0.061 a b$ & Wk. 1 & $0.287 \pm 0.061 \mathrm{ab}$ \\
\hline (Indicator of phenolic & & & Wk. 3 & $0.175 \pm 0.023 b$ & Wk. 3 & $0.196 \pm 0.036 \mathrm{bcd}$ & Wk. 3 & $0.155 \pm 0.032 \mathrm{~cd}$ \\
\hline compounds degradation & $0.263 \pm 0.025 a$ & $0.244 \pm 0.026 a$ & Wk. 6 & $0.161 \pm 0.018 b$ & Wk. 6 & $0.170 \pm 0.025 \mathrm{bcd}$ & Wk. 6 & $0.151 \pm 0.029 \mathrm{~d}$ \\
\hline juice) & & & Wk. 9 & $0.318 \pm 0.03 a$ & Wk. 9 & $0.283 \pm 0.023 \mathrm{ab}$ & Wk. 9 & $0.352 \pm 0.051 a$ \\
\hline & & & Wk. 12 & $0.327 \pm 0.034 a$ & Wk. 12 & $0.379 \pm 0.046 a$ & Wk. 12 & $0.275 \pm 0.03 a b c$ \\
\hline & & & Wk. 1 & $0.310 \pm 0.035 \mathrm{~d}$ & Wk. 1 & $0.310 \pm 0.055 \mathrm{e}$ & Wk. 1 & $0.310 \pm 0.055 \mathrm{e}$ \\
\hline & & & Wk. 3 & $0.626 \pm 0.126 \mathrm{bc}$ & Wk. 3. & $0.438 \pm 0.034 \mathrm{de}$ & Wk. 3. & $0.814 \pm 0.207 \mathrm{bc}$ \\
\hline $\begin{array}{l}\text { Browning Index (BI) } \\
\text { of the extracted juice }\end{array}$ & $0.651 \pm 0.088 a$ & $0.595 \pm 0.069 a$ & Wk. 6 & $0.442 \pm 0.016 \mathrm{~cd}$ & Wk. 6. & $0.444 \pm 0.03$ de & Wk. 6. & $0.440 \pm 0.018$ de \\
\hline & & & Wk. 9 & $0.930 \pm 0.116 a$ & Wk. 9 & $1.112 \pm 0.101 a$ & Wk. 9. & $0.748 \pm 0.153 b c$ \\
\hline & & & Wk. 12 & $0.806 \pm 0.079 a b$ & Wk. 12 . & $0.950 \pm 0.05 a b$ & Wk.12. & $0.662 \pm 0.088 \mathrm{~cd}$ \\
\hline
\end{tabular}

-Data presented as the Mean \pm ST.DEV. Mean comparisons and LSD between pairs was determined by Student's t test $(\alpha=0.05)$. For each effect source, levels or means that are not connected by the same letter are significantly different $(\mathrm{p}<0.05)$.

\section{Figures}




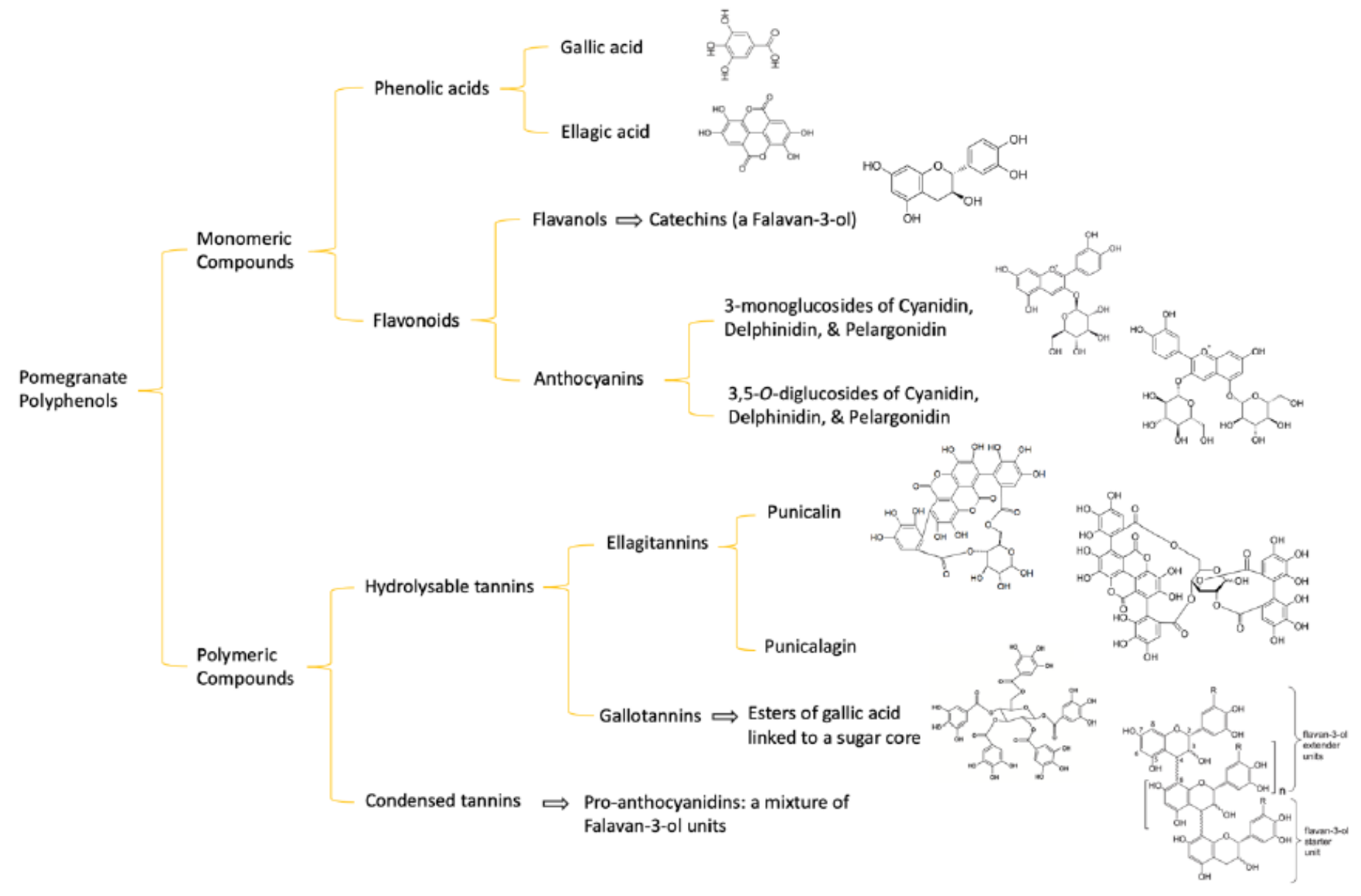

Figure 1

A diagram of pomegranate fruit known phenolic compounds. 


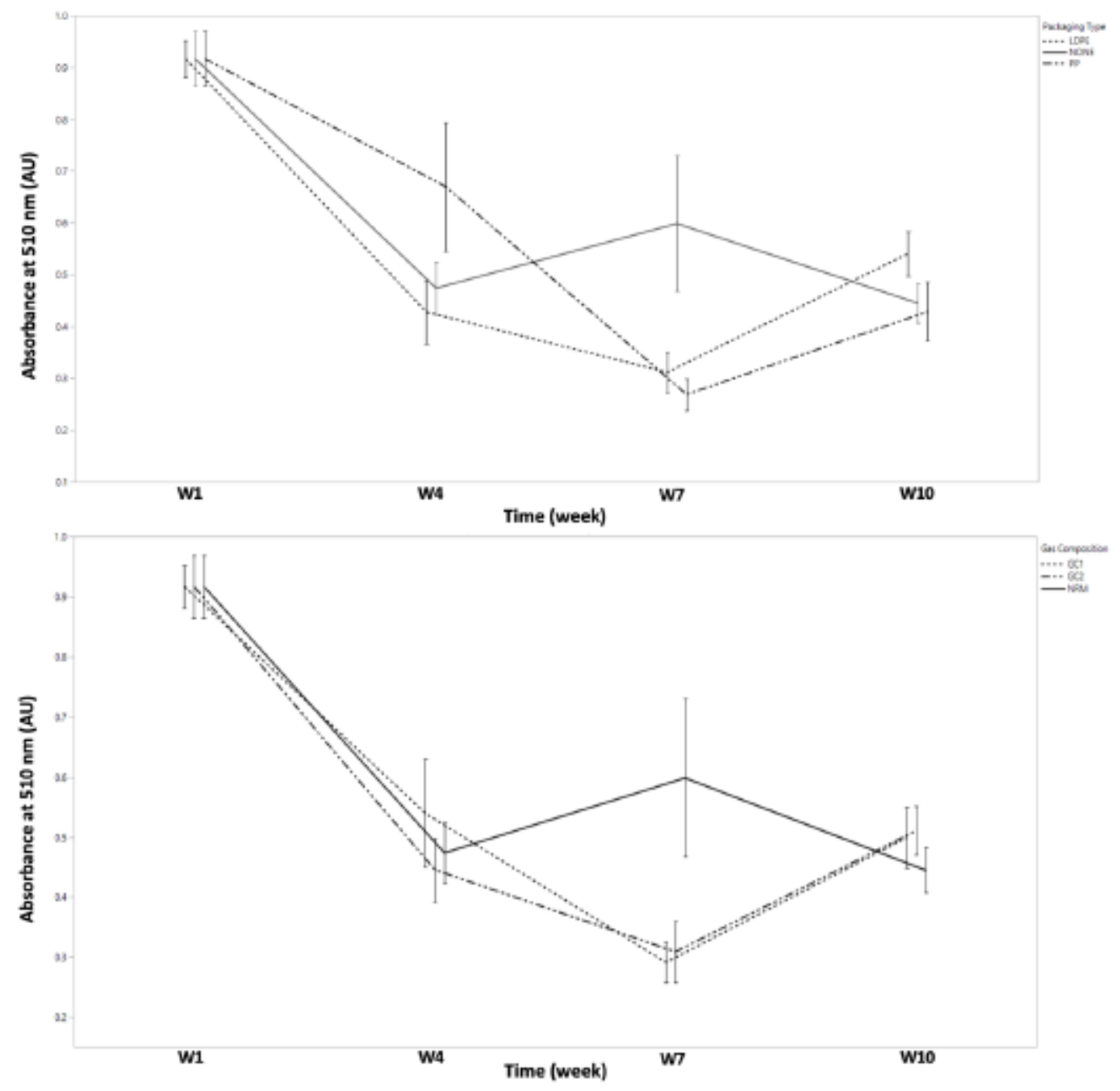

Figure 2

Effects of packaging type (top) and gas compositions (bottom) on the total anthocyanins content during the 10 weeks of storage. Each error bar is constructed using 1 standard error from the mean. Packaging type: PP, polypropylene; LDPE, low-density polyethylene; NONE, no packaging is used. Gas composition: NRM, air or ambient atmosphere; GC1, initial MAP with $5 \%$ CO2 and 5\% O2; GC2, initial MAP with $10 \%$ $\mathrm{CO} 2$ and $5 \% 02$. 


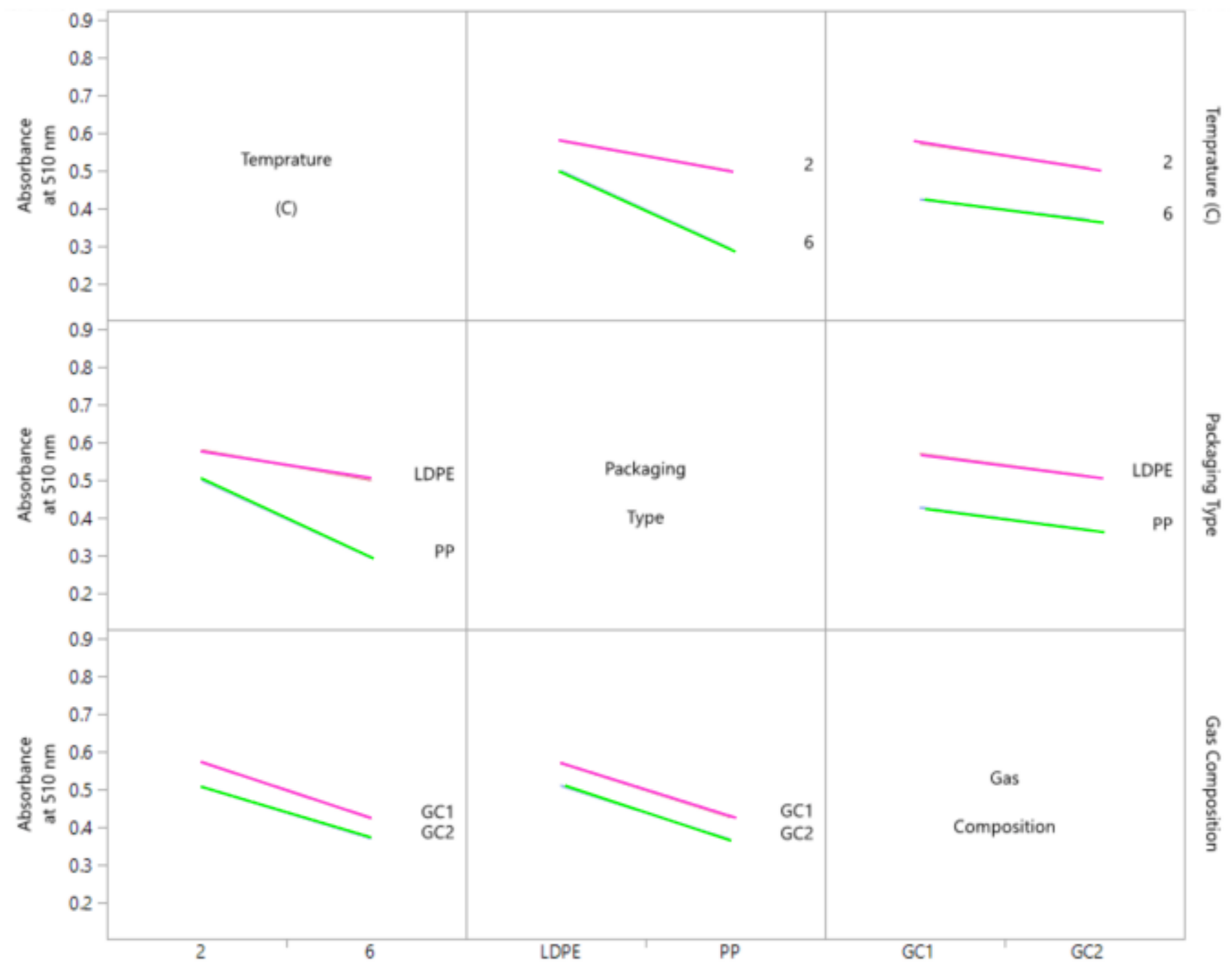

Figure 3

Interaction profile of temperature, packaging type, and gas composition effects on the total anthocyanins content of the MA packaged pomegranates. Packaging type: PP, polypropylene; LDPE, low-density polyethylene. Gas composition: GC1, initial MAP with 5\% CO2 and 5\% O2; GC2, initial MAP with $10 \%$ CO2 and $5 \% 02$. 

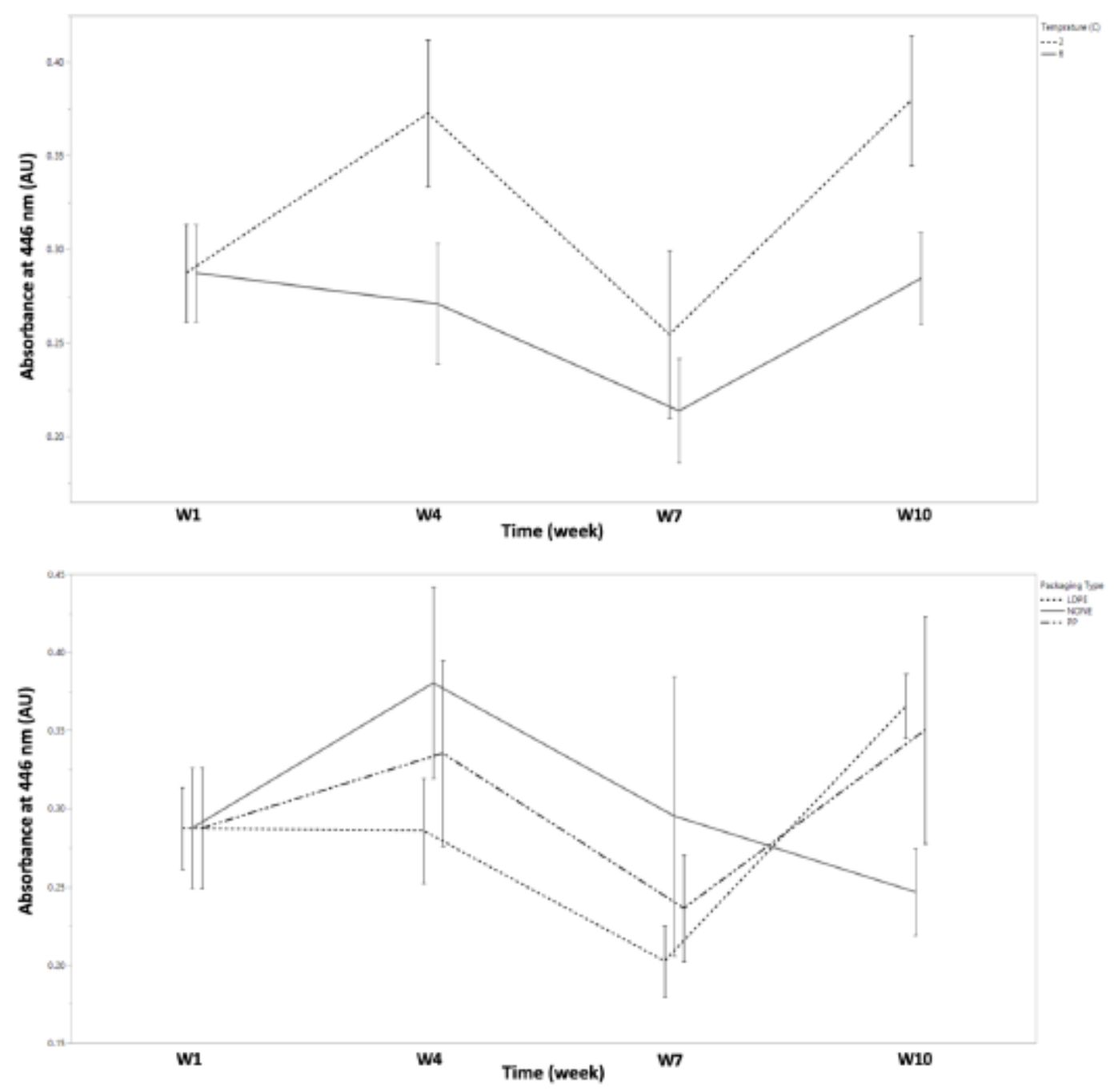

Figure 4

Effects of Storage temperature (top) and type of packaging (bottom) on development of browning compounds over 10 weeks of storage. Each error bar is constructed using 1 standard error from the mean. Packaging type: PP, polypropylene; LDPE, low-density polyethylene; NONE, no packaging is used. 


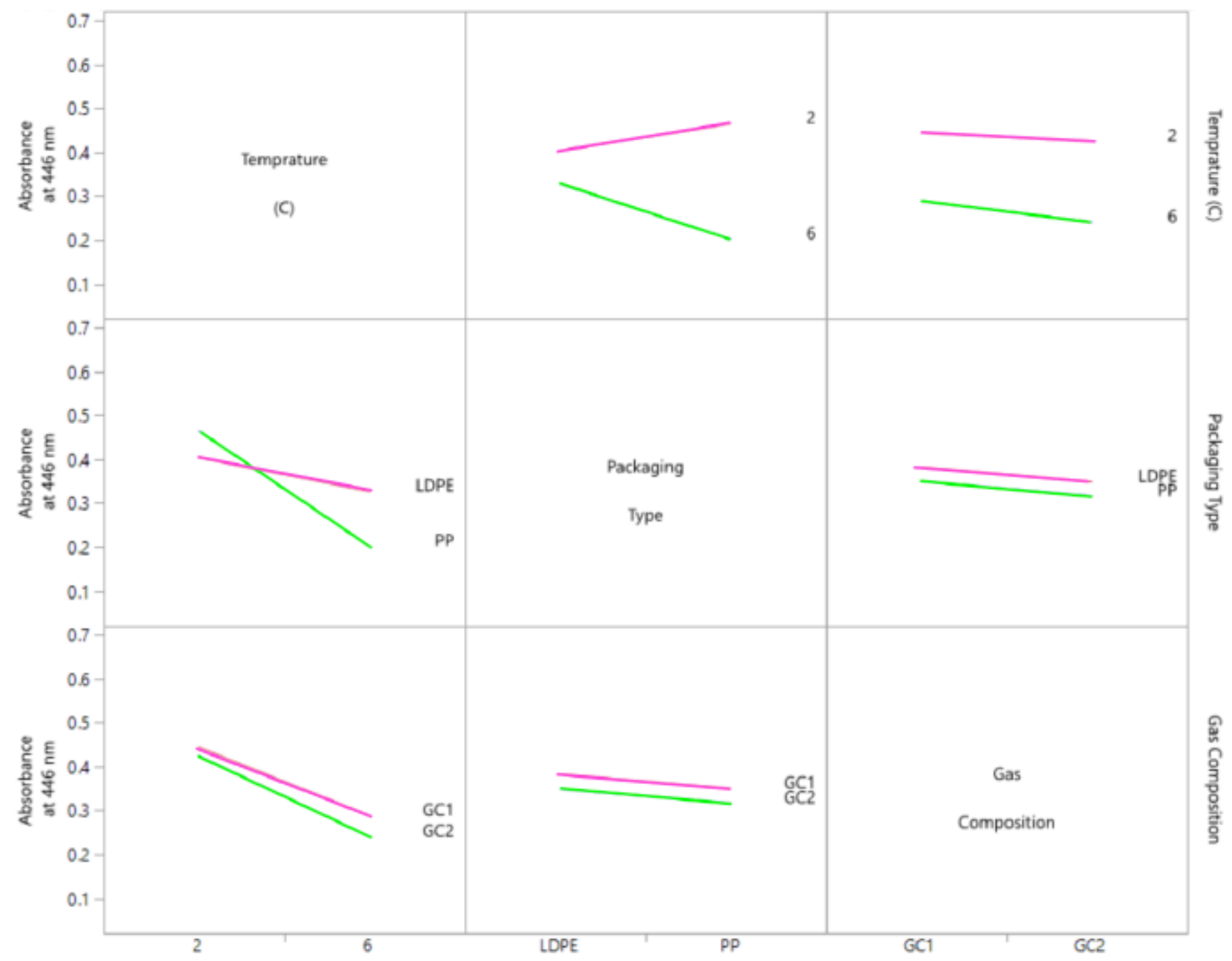

Figure 5

Interaction profile of temperature, packaging type, gas composition effects on the development of phenolic compounds degradation products of MA packaged pomegranates. Packaging type: PP, polypropylene; LDPE, lowdensity polyethylene. Gas composition: GC1, initial MAP with $5 \% \mathrm{CO} 2$ and $5 \%$ 02; GC2, initial MAP with $10 \%$ CO2 and 5\% 02 . 


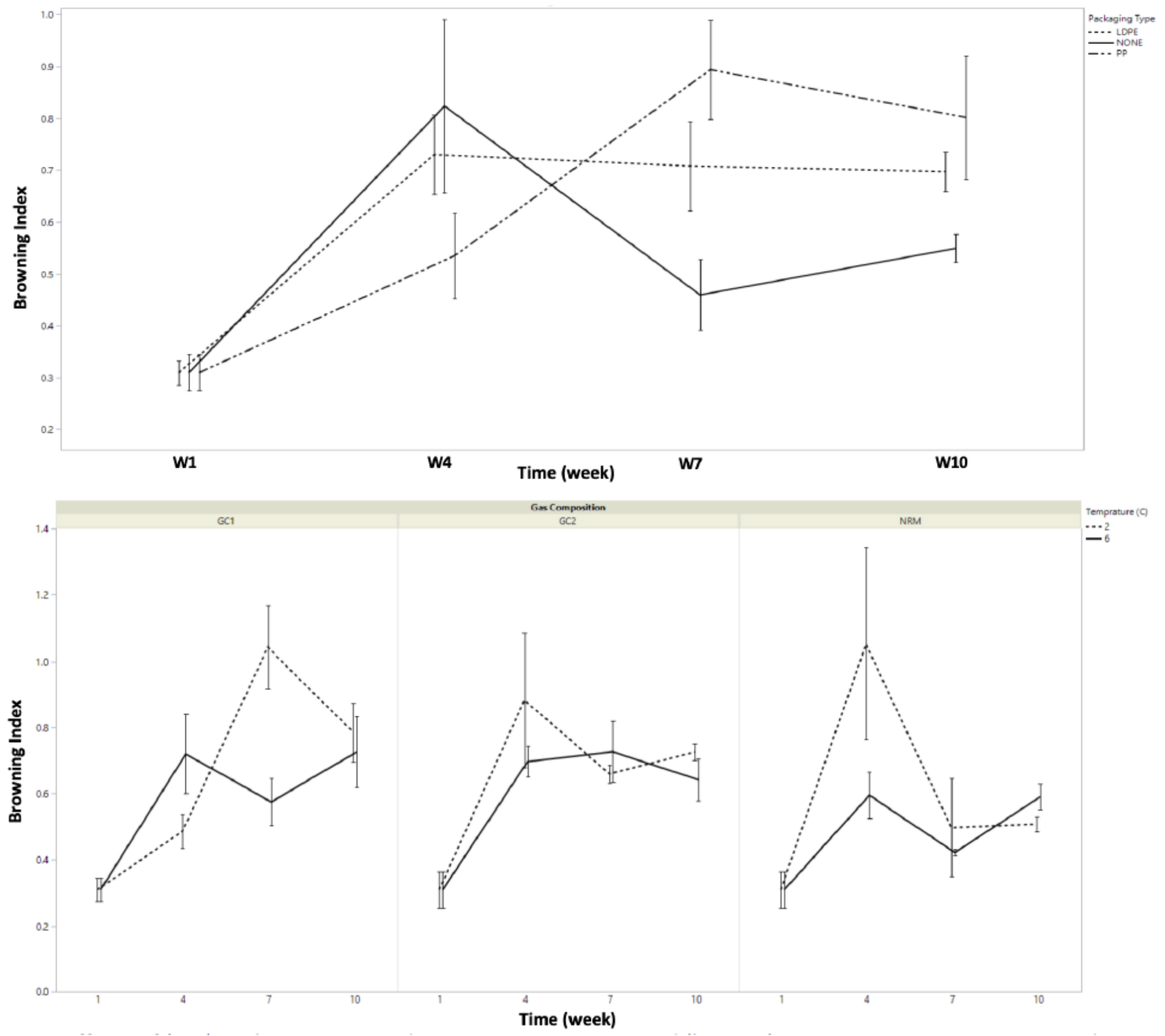

Figure 6

Effects of (top) packaging type and storage temperature, and (bottom) storage temperature, time, and gas composition on the values of Browning Index (BI) during 10 weeks storage. Each error bar is constructed using 1 standard error from the mean. Packaging type: PP, polypropylene; LDPE, low-density polyethylene; NONE, no packaging is used. Gas composition: NRM, air or ambient atmosphere; GC1, initial MAP with $5 \%$ CO2 and 5\% 02; GC2, initial MAP with $10 \%$ CO2 and $5 \% 02$. 

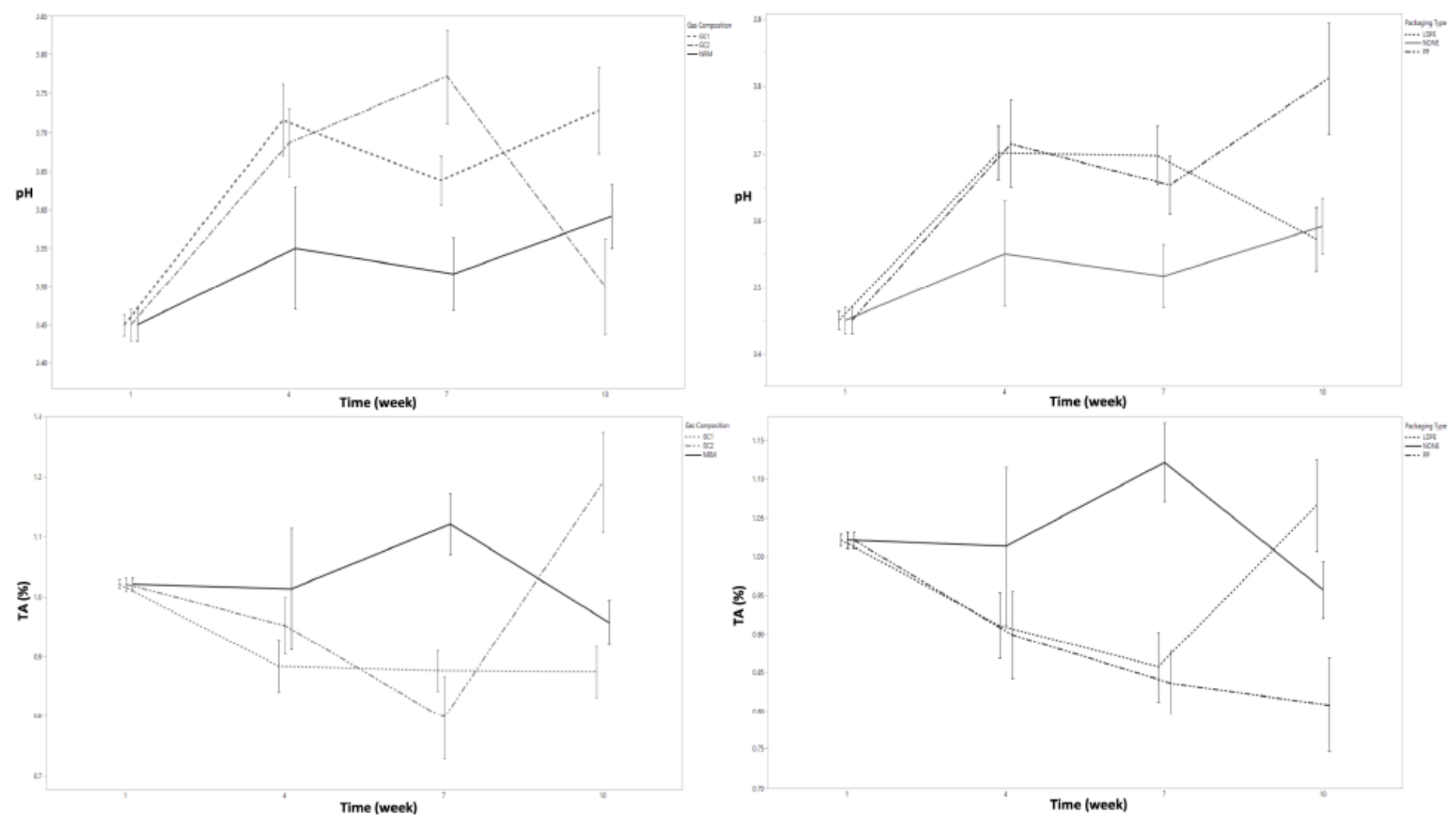

\section{Figure 7}

Effects of packaging type and surrounding gas composition on the (top) $\mathrm{pH}$, and TA (bottom) of pomegranates during 10 weeks of storage. Each error bar is constructed using 1 standard error from the mean. Packaging type: PP, polypropylene; LDPE, low-density polyethylene; NONE, no packaging is used. Gas composition: NRM, air or ambient atmosphere; GC1, initial MAP with $5 \% \mathrm{CO} 2$ and $5 \% \mathrm{O} 2$; GC2, initial MAP with $10 \% \mathrm{CO} 2$ and $5 \% 02$. 


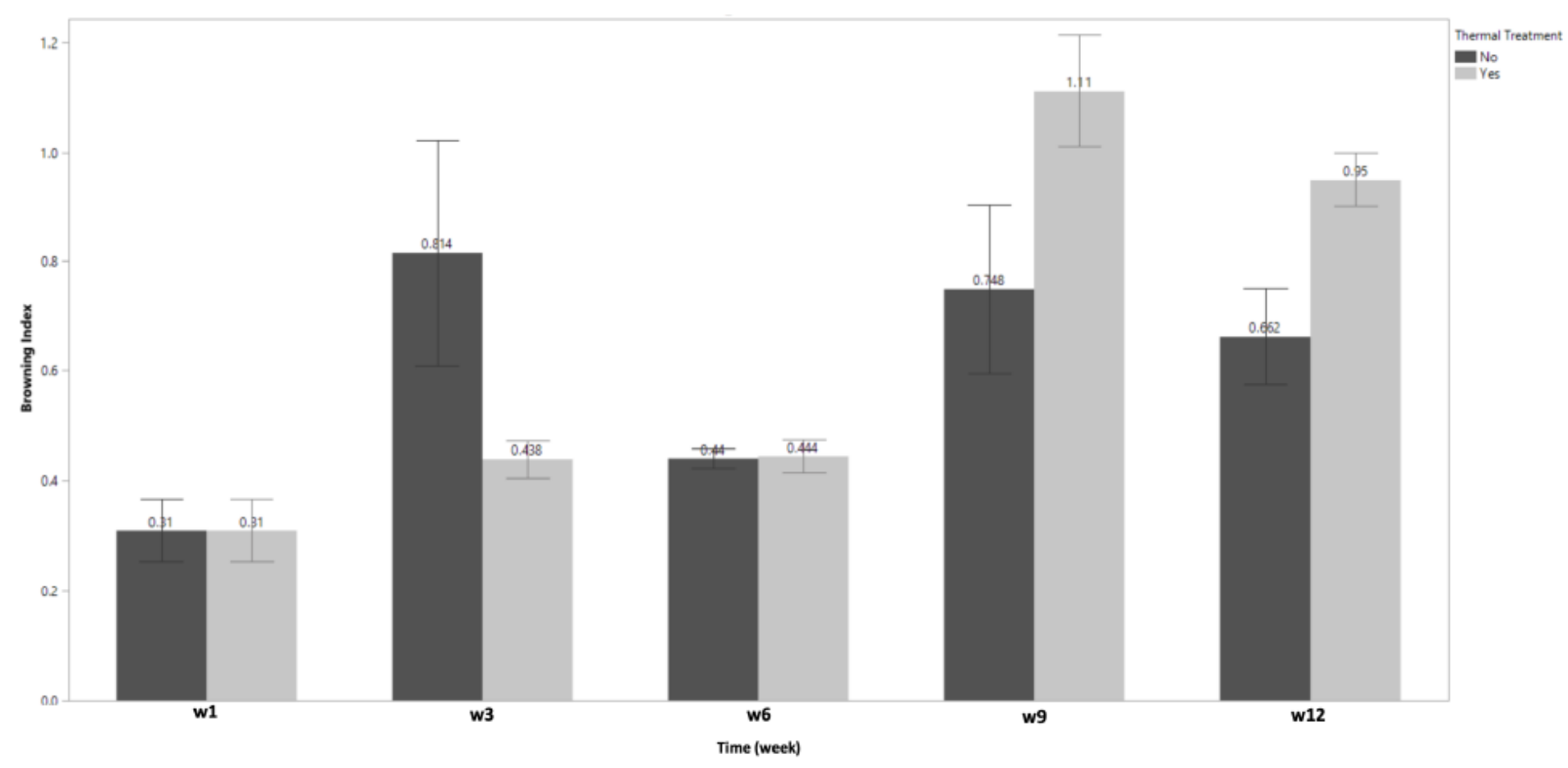

Figure 8

Effects of thermal dipping treatment on the values of Browning Index (BI) during 12 weeks of storage. Each error bar is constructed using 1 standard error from the mean. without thermal dipping treatment; with thermal treatment.

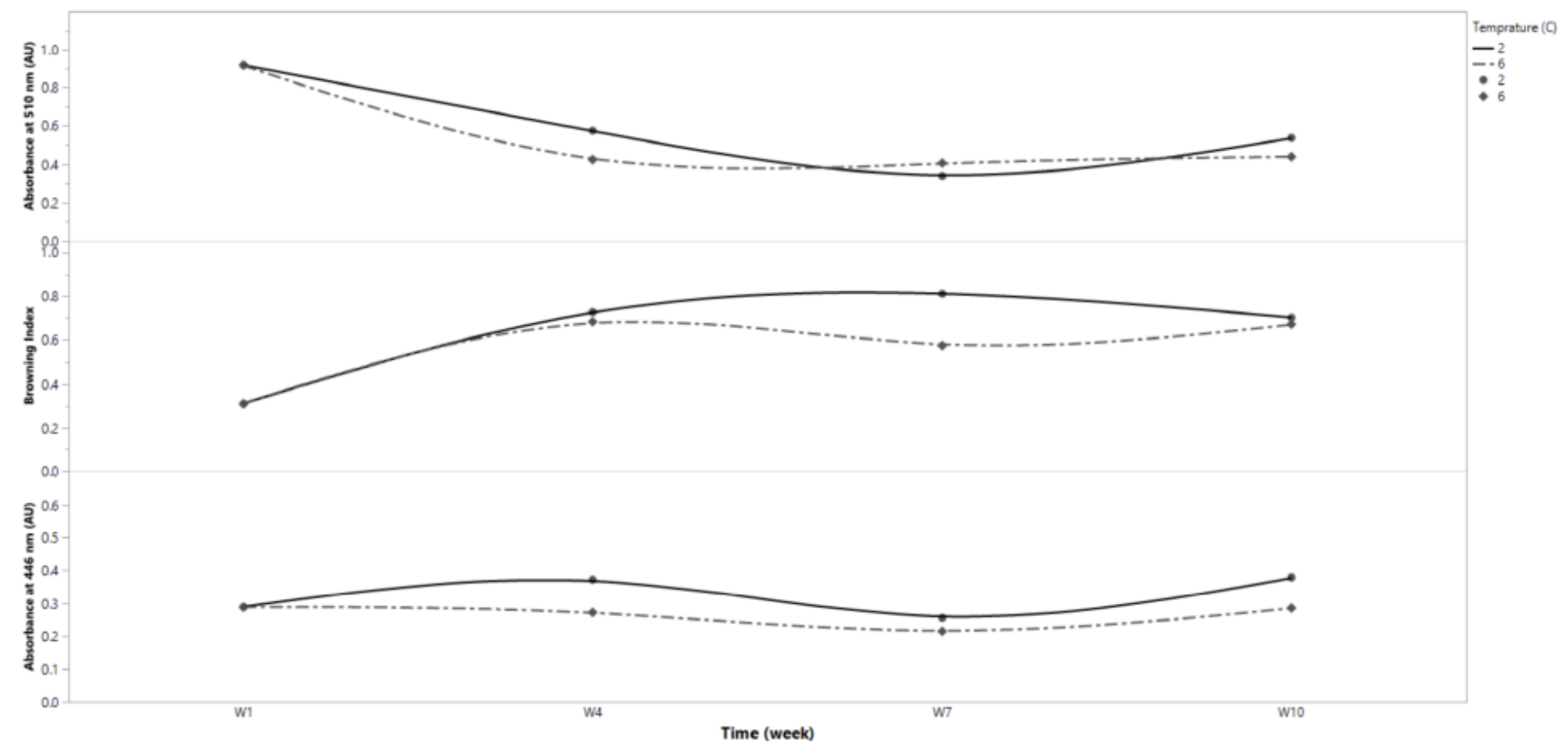

Figure 9 
Profiles of changes in the (top) total anthocyanins, (middle) browning index, and (bottom) development of browning pigments during 10 weeks of storage at $2{ }^{\circ} \mathrm{C}(-)$ and $6{ }^{\circ} \mathrm{C}(-)$.

a)

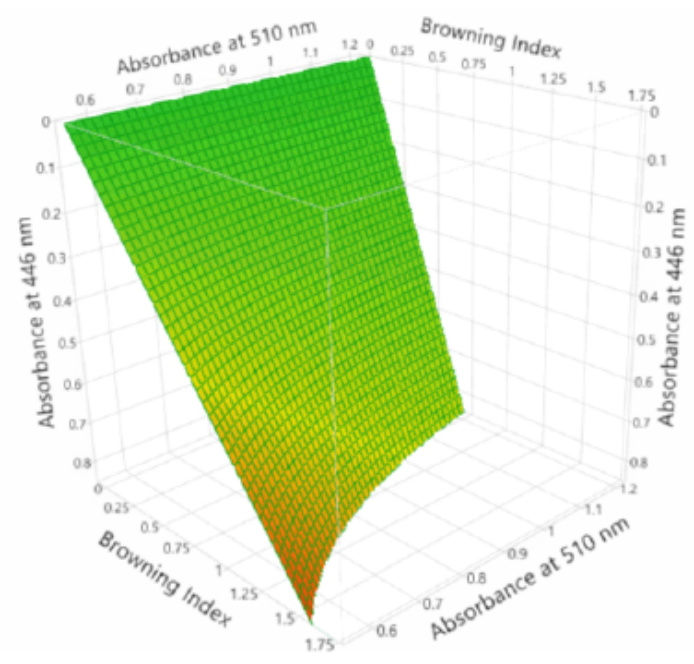

b)

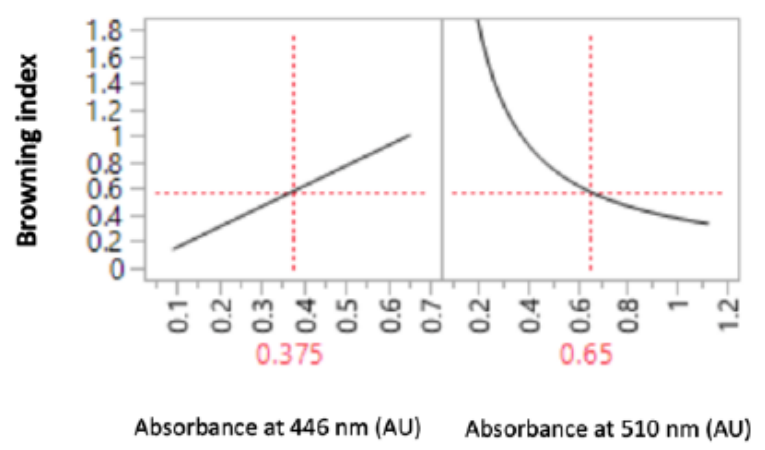

\section{Figure 10}

(a) Response surface 3D showing changes in the Browning Index (BI) of the extracted juice in relation to the total anthocyanins content (absorbance at $510 \mathrm{~nm}$ ) and phenolic compound degradation products (absorbance at $446 \mathrm{~nm}$ ) during storage, and (b) prediction profiler for the anticipated Browning Index.

\section{Supplementary Files}

This is a list of supplementary files associated with this preprint. Click to download.

- GraphicalAbstract.png 